\title{
Significados, para os familiares, de conviver com um idoso com sequelas de Acidente Vascular Cerebral (AVC)
}

\author{
Rogério Donizeti Reis(a) \\ Elaine Cristina Pereira ${ }^{(b)}$ \\ Maria Isabel Marques Pereira ${ }^{(c)}$ \\ Ana Maria Nassar Cintra Soane ${ }^{(\mathrm{d})}$ \\ José Vitor da Silva ${ }^{(e)}$
}

Reis RD, Pereira EC, Pereira MIM, Nassar AM, Soane C, Silva JV. Meanings to family members living with an elderly affected by stroke sequelae. Interface (Botucatu). 2017;

21(62):641-50.

The objective of this study is to identify the meanings for relatives who live with an elderly with stroke sequelae. The study participants were family members cohabiting with elderly men and women with stroke sequelae. The sample consisted of 15 family members. Data was gathered using a questionnaire on personal and family characteristics of the participants and semi-structured interviews. We used the Bardin Content Analysis in order to extract the main ideas. The emerging categories for the theme 'meaning of living together' were 'a painful experience', 'habits and life changes', 'a very difficult situation', 'to be resilient' and 'the difficulty of the individual in accepting the disease'. We conclude that living with elderly individuals with stroke sequelae has physical, psychological and familial implications.

Keywords: Elderly. Stroke. Family.
O objetivo deste estudo é identificar os significados para os familiares de conviver com idosos com sequelas de AVC. Os participantes do estudo foram os familiares que conviviam com idoso do gênero masculino e feminino. A amostra foi constituída por 15 membros familiares. Os instrumentos utilizados para a coleta de dados foram questionário referente à caracterização pessoal e familiar dos participantes e o roteiro de entrevista semiestruturada. Para extração das ideias principais, foi utilizada a Análise de Conteúdo de Bardin. As categorias emergentes do tema 'Significado de conviver' foram 'Experiência dolorosa', 'Mudança de hábito e de vida', 'Uma situação muito difícil', 'Ser resiliente' e 'Dificuldade da pessoa em aceitar a doença'. Conclui-se que conviver com idosos com sequelas de AVC assume caráter com implicações físico-psicológicas e familiares.

Palavras-chave: Idoso. Acidente vascular cerebral. Família.

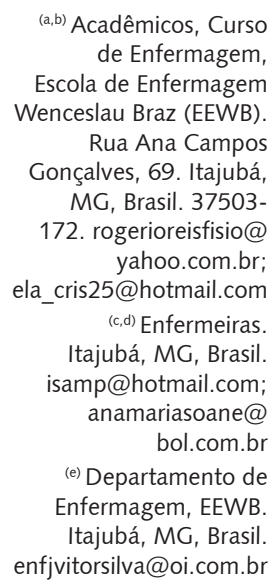

${ }^{(a, b)}$ Acadêmicos, Curso de Enfermagem, Escola de Enfermagem Wenceslau Braz (EEWB). Rua Ana Campos Gonçalves, 69. Itajubá, MG, Brasil. 37503-

172.rogerioreisfisio@ yahoo.com.br; ela_cris25@hotmail.com (c,d) Enfermeiras. Itajubá, MG, Brasil. isamp@hotmail.com; anamariasoane@ bol.com.br

(e) Departamento de Enfermagem, EEWB.

Itajubá, MG, Brasil. enfjvitorsilva@oi.com.br 


\section{Introdução}

Vários são os estudos que nos mostram a importância da saúde e qualidade de vida (QV) do ser idoso e do processo de envelhecimento populacional. Isso se torna relevante a partir do momento em que o idoso adoece e tem sua capacidade física, social, psicológica e espiritual transformada, deixando de ser um idoso ativo e produtivo para ser um sujeito totalmente dependente, como nos casos das doenças crônicas degenerativas, dentre as quais o acidente vascular cerebral (AVC).

O idoso enfrenta restrições, no dia a dia, da sua caminhada, desde aspectos psicológicos, emocionais, sociais e, sobretudo, físicos, como: lentificação da marcha, instabilidade postural, presbiacusia e déficit visual. Esses são exemplos de deteriorações que o levam a um quadro de dependência acerca das atividades de vida diária e, no caso do idoso com AVC, tais limitações são nítidas, diminuindo, assim, sua autonomia.

As restrições do dia a dia levam a família a se responsabilizar pela prestação de cuidados na saúde e na doença dos seus entes queridos. É na família que se aprende o autocuidado, adquiremse comportamentos de bem-estar, prestam-se cuidados a diferentes membros ao longo do seu desenvolvimento e durante as diferentes transições do ciclo vital. Habitualmente, os diferentes membros que a compõem apoiam-se uns aos outros em atividades de promoção de saúde e nos processos de doença aguda e/ou crônica'.

É na especificidade do cuidar de um familiar em nosso país que surgem, ainda, sentimentos ambivalentes que se caracterizam por satisfação, generosidade, afeto e amor, assim como por sobrecarga, sofrimento, incerteza e estresse.

Em todos os países, existe uma preocupação com o envelhecimento da população. Segundo Fabrício ${ }^{2}$, vários estudos voltam-se para um envelhecimento saudável e ativo, pautados em experiências positivas e oportunidades seguras de saúde, com potencial para o bem-estar físico, social e mental, com valorização da capacidade funcional.

De acordo com o Instituto Brasileiro de Geografia e Estatística ${ }^{3}$, a expectativa de vida do brasileiro subiu para 74,9 anos em 2014. Em 2013, a expectativa era 74,6 anos. Esse índice aumentou em 11 anos nas últimas três décadas, o que é um fato positivo, porém preocupante, pois, com o aumento, existe maior prevalência de doenças crônicas degenerativas, e, sem dúvida, um melhor preparo dos profissionais de saúde se torna necessário para atender as necessidades das famílias, do idoso e da comunidade ${ }^{2}$.

Os acidentes vasculares cerebrais são um importante problema de saúde pública, com uma taxa de alta letalidade e uma percentagem significativa de sobrevivente dependente. Com efeito, a cada ano, 15 milhões de pessoas no mundo sofrem um AVC. Gomes ${ }^{4}$ diz que, deste número, cinco milhões de pessoas morrem e outros cinco milhões sobrevivem com uma incapacidade permanente, causando graves consequências em termos pessoais, familiares e de comunidade. Nessa conjuntura, o AVC tem grande capacidade de gerar déficit no funcionamento físico, sensorial e cognitivo, com impacto no dia a dia e no desempenho do indivíduo, no que diz respeito às atividades da vida diária.

No Brasil, apesar do declínio das taxas de mortalidade, o AVC representa a primeira causa de morte e incapacidade no país, o que interfere em grande impacto econômico e social. Dados provenientes de estudo prospectivo nacional indicaram incidência anual de 108 casos por 100 mil habitantes, taxa de fatalidade aos trinta dias de 18,5\%, e, aos 12 meses, de 30,9\%, sendo o índice de recorrência após um 1 é de $15,9 \%$ (datasus) $^{5}$.

Para Girardon ${ }^{6}$, a incapacidade funcional dos atingidos, muitas vezes, resulta na restrição ou limitação dos movimentos, tornando-os incapazes de realizarem sozinhos suas atividades da vida diária e outras tarefas. Perante a limitação, passam a depender do auxílio de outrem. Essa restrição que cerceia suas ações acaba por Ihes comprometer, também, a capacidade de decidir sobre o que e quando desejam realizar determinada atividade, perdendo, assim, sua independência e autonomia.

Araújo et al. ${ }^{7}$ relatam que as sequelas e os sentimentos de angústia afetam diretamente o cuidado prestado ao ser e, por fim, a oferta de maiores esforços para a qualidade de vida do paciente. Para primar pela melhora da independência e autonomia do outro, esses sentimentos devem ser controlados. Os cuidadores devem se apresentar dotados do sentimento de cuidar, pois, dessa forma, 
é possível atrelar o cuidado aos aspectos imperativos da individualidade do ser, seguindo o modelo holístico de cuidado, bastante defendido pela enfermagem atual, que leve o sujeito à maior autonomia e independência.

Considerando o que foi exposto anteriormente, o objetivo deste estudo constitui identificar o significado, para os familiares, de conviver com um membro idoso com sequelas de AVC.

\section{Método}

O presente estudo foi elaborado de acordo com a abordagem qualitativa do tipo exploratório, descritivo e transversal. Os participantes do estudo foram os familiares que conviviam no dia a dia com o idoso com sequelas de AVC. Este estudo teve como cenário a cidade de Itajubá/MG no que tange aos seus diversos bairros, tanto da zona urbana quanto rural, onde viviam pessoas idosas com sequelas de AVC e seus familiares. A amostra constituiu-se de 15 cuidadores informais após técnica de saturação e a amostragem foi a técnica Snowball (bola de neve).

Os critérios de inclusão foram:

- Ter um membro familiar idoso com sequelas de AVC e que necessite de ajuda nas atividades de vida diária;

. Ser cuidador informal;

- Conviver com o idoso com sequelas de AVC, prestando-lhe cuidado direto há, pelo menos, seis meses. O critério de inclusão de ter, no mínimo, seis meses de experiência deve-se ao fato de que, segundo Monteiro $^{8}$, toda adaptação a qualquer situação nova ocorre, geralmente, após o período de vivência e experiência;

- Ser maior de 18 anos;

- Aceitar participar do estudo, assinando o Termo de Consentimento Livre e Esclarecido.

O critério de exclusão se limitou a serem cuidadores informais de idosos com capacidade cognitiva e de comunicação comprometidas.

O presente estudo obedeceu aos preceitos estabelecidos pela Resolução n 466/12, de 12 de dezembro de 2012, do Ministério da Saúde, que trata da ética em pesquisa envolvendo seres humanos. O parecer consubstanciado que aprova a realização do estudo encontra-se sob o $\mathrm{n}^{\circ}$ 889.895/2014.

Os dados foram colhidos nos domićlios. A coleta de dados teve início após a aprovação do estudo pelo Comitê de Ética em Pesquisa (CEP) da Escola de Enfermagem Wenceslau Braz. Foi obtida a anuência do entrevistado por meio da assinatura do Termo de Consentimento Livre e Esclarecido. A entrevista foi realizada após agendamento prévio com cada um dos participantes, em local e data determinados pelos familiares. Antes da realização da entrevista, os pesquisadores explicaram os objetivos do estudo, assim como o desenvolvimento de todo o trabalho, e foram esclarecidas todas as dúvidas. Teve-se o cuidado de manter um ambiente calmo e tranquilo, isento de ruídos, proporcionando privacidade e segurança. Após a entrevista gravada, foi feita a transcrição.

Para a entrevista, foram utilizados dois instrumentos durante a coleta de dados: um questionário referente às características sociodemográficas do cuidador; e, o segundo, constituiu um roteiro de entrevista semiestruturada, contendo uma pergunta norteadora: 'Fala para mim o que significa conviver com um idoso com sequelas de AVC?'

$\mathrm{Na}$ estratégia de análise de dados, o método escolhido foi a Análise de Conteúdo de Bardin? .

\section{Resultados e discussão}

Diante do levantamento das características pessoais e familiares dos participantes da pesquisa, obtivemos, como resultado, a prevalência do sexo feminino, com 73,33\%; a idade média foi de $58,20$ anos ( $D P=16,70) ; 46,67 \%$ concluíram o Ensino Médio. Dentre as profissões, destacaram-se: 
comerciantes, do lar, técnico de enfermagem e enfermeira, com 13,33\% cada, e 53,33\% não são aposentados. Os que professam a religião católica perfizeram $60 \%$. De todo o universo entrevistado, $40 \%$ eram filhas, e o tempo de convivência variou entre um e dois anos, equivalendo a $33,33 \%$. No que se refere à caracterização dos familiares entrevistados, 53,33\% eram membros de uma família extensa. No que concerne à renda familiar, $26,66 \%$ possuíam de três a quatro salários. Os que residiam em casa própria totalizaram $86,66 \%$.

Do tema explorado: 'conviver com idoso com sequelas de AVC' emergiram as categorias do Quadro 1.

Quadro 1. Categorias relacionadas ao aspecto conviver

\begin{tabular}{|l|c|}
\hline \multicolumn{1}{|c|}{ Conviver } & Frequência \\
\hline Experiência dolorosa & 11 \\
\hline Mudança de hábito e de vida & 10 \\
\hline Uma situação muito difícil & 7 \\
\hline Ser resiliente & 7 \\
\hline Dificuldade da pessoa em aceitar a doença & 3 \\
\hline
\end{tabular}

Fonte: dos autores.

Em relação ao aspecto 'conviver com idoso com sequelas de $A V C$ ', foram evidenciadas cinco categorias descritas abaixo: 'experiência dolorosa', 'mudança de hábito e de vida', 'uma situação muito difícil', 'ser resiliente', 'dificuldade da pessoa em aceitar a doença'.

Refletindo a categoria 'experiência dolorosa', o participante relatou:

Eu nunca tinha passado por essa experiência, não esperava passar. É muito triste, principalmente ver a mãe da gente sofrendo assim. A gente fica muito nervosa, aflita, sem saber o que fazer... Perdida. É complicado. A gente vai dar comida, não quer. Dá remédio, ela cospe. Sabe? Se vai trocar, ela grita. Não é fácil não. Dar banho, acamada, não vira, não se mexe, então, vai complicando. Começa a aparecer cada dia uma coisa nova: um dia está irritada, outro dia brava. É a pior coisa que eu já passei na minha vida, sinceramente. (p. 4)

É possível perceber que cada família é única e passa por processos diversificados, vivenciando-os de maneira particular. Portanto, é necessário conhecer e compreender os seus comportamentos. Diante de uma doença crônica, cada membro da família reage de forma inesperada: enquanto alguns assumem atitudes de superação, outros regridem no seu caminhar definitivamente. Alguns não assumem quaisquer cuidados, abstêm-se inteiramente devido ao sofrimento mútuo. Ainda há aqueles em que a relação pode se desenvolver sem participação e envolvimento harmonioso entre ambos, inclusive na falta de interesse e retribuição pelos idosos com sequelas de AVC.

Diante do exposto, quando se depara com uma situação de doença na família, o que se evidenciam, muitas vezes, são experiências difíceis, atribuladas e que causam grande comoção. O sofrimento é nítido devido à capacidade do ser humano para se compadecer com a fragilidade do outro. Para Mendonça, Garanhani e Martins ${ }^{10}$, sentimentos como revolta, frustração e clausura podem ser empiricamente evidenciados no ambiente em que se encontra o idoso com AVC.

O AVC pode ser considerado um evento novo e inesperado na vida tanto do paciente quanto daqueles que formam sua rede social. Do mesmo modo, é importante que a família, também adoecida, esteja amparada nesses momentos de crise, dúvidas e incertezas. Portanto, é imprescindível pensar nas necessidades e desejos destes sujeitos, objetivando prepará-los para o cuidado no domicílio ${ }^{11}$.

Ainda segundo Paiva e Valadares ${ }^{11}$, as doenças crônicas degenerativas, como o AVC, evidenciam o papel da família como centro de prestação de cuidados. 
Frente ao adoecimento de um membro, todos os outros são atingidos. Cabe pensar que é no contexto familiar que a doença evolui, surgem os problemas e as possíveis soluções. Os familiares vivenciam e se envolvem em todas as fases do adoecer, oferecendo suporte no cuidado ao doente.

Assim, a doença, especialmente a crônica, é sempre um acontecimento estressor que produz efeitos no paciente e na família, e esta, ao vivenciar a crise, experimenta, inicialmente, um desequilíbrio em sua capacidade de funcionamento normal, provocando alterações que envolvem afeto, finanças e relações de poder, implicando um processo de reorganização familiar. O cuidado familiar surge, então, como parte importante das ações de manutenção da autonomia, integração e participação do idoso nas relações e na sociedade ${ }^{12}$.

Concomitantemente à experiência dolorosa, há, também, uma mudança de hábito e de vida, fato evidenciado na fala do participante:

\begin{abstract}
Significa toda uma mudança de hábito, de vida, de hora, de tudo. Tivemos que construir uma nova vida, uma nova caminhada. Por que antes nós não pensávamos no outro. Assim, saia sem se preocupar, não tinha hora pra chegar. Quando o pai teve o AVC e levamos ele lá pro hospital... Nossa um AVC! O que vai ser da nossa vida agora? O que vai ser da vida do pai agora? Ele, que era uma pessoa tão ativa, tão pra frente. Aí, traz ele pra casa desse jeito, ele completamente debilitado. No começo foi muito difícil. A gente teve que fazer tudo pro pai. Muito difícil. Então, foi uma mudança radical nas nossas vidas. Então, assim, é um reaprender, um reviver de novo. A gente está lutando contra essas mudanças, mas está sendo difícil. Cada dia é um dia. A gente sai, mas sai pensando na pessoa que está com ele. O que será que está acontecendo? Será que está bem? Será que não está? E ele assim... Hoje o pai, o pai é uma criança grande, por que mesmo tendo a cabecinha aparentemente normal, o pai é uma criança. Não tem mais suas vontades próprias. Ele vive em função do que a gente fala. Faz isso, faz aquilo, levanta, acorda. Então ele vive em função nossa e a gente em função dele. (p. 3)
\end{abstract}

Nota-se que o membro familiar teve de construir uma nova vida, uma nova caminhada e uma nova identidade, cujo desafio de conviver tornou-se aspecto crucial.

O membro familiar que assume o convívio deve adquirir novos hábitos. A sua vida é toda transformada. Há uma mudança por completo, que vai desde assuntos menos relevantes do cotidiano, até temas significativos, como viagem, férias e privacidade.

Com isso, o cuidador se vê na necessidade de aprender a encontrar atalhos no dia a dia para contornar as diversas situações que acarretam mudanças radicais do seu agir, da sua convivência e, sobretudo, da sua vida. Salienta-se que a mudança no hábito de vida é um reaprender e um desafio de reviver. As alterações sociais são situações preponderantes que levam à estagnação da continuidade de uma qualidade de vida harmoniosa, fato percebido quando o cuidador se depara perante um familiar idoso que necessita de assistência continuada. E isso provoca revolta, angústia e insatisfação, privando-o de alguns prazeres.

É de suma importância a identificação das mudanças que ocorrem no cuidador que está envolvido no convívio com a pessoa em situação de AVC, para, assim, poder evitar os efeitos mais negativos, promovendo a saúde das pessoas, tanto com dependência quanto de si próprios, e contribuindo para a estabilidade e melhorias nas relações familiares.

Ao prestar cuidados, o cuidador passa a ter menos tempo para cuidar de si, descansando menos e trabalhando mais, ou seja, privando-se do convívio social, uma vez que o doente acometido por AVC se torna o centro das atenções. Esses fatores levam o cuidador à reacomodacão de suas práticas diárias, privilegiando as atividades exigidas em favor do quadro da doença, submetendo-se, assim, a uma sobrecarga física e emocional relacionada à intensidade de cuidados prestados ${ }^{7}$.

A sobrecarga é um fator preocupante, pois leva o indivíduo ao desenvolvimento da fadiga ocupacional. Quando somada à prestação de cuidados, atividade que exige determinação, destreza e atenção, por parte do executante, pode levar ao desgaste emocional e, possivelmente, ao desequilíbrio no processo de saúde e doença. Daí a necessidade de que tanto ele quanto o idoso acometido por AVC tenham necessidade de cuidados especiais ${ }^{7}$. 
Ohara et al. ${ }^{13}$ são sucintos ao dizer que, por se tratar de uma síndrome multifatorial, é de grande importância compreender as relações entre o idoso fragilizado e seu contexto familiar no que refere ao cuidado, porque o cuidar do idoso de alta dependência no domicílio modifica toda a dinâmica da família.

Para Pavin e Carlos $^{14}$, o ato de cuidar e o convívio demandam responsabilidade e tempo de quem exerce tal função. Os cuidadores vivenciam diversas situações difíceis, permeadas por mudanças em suas vidas, as quais podem ser de ordem econômica, física, emocional e espiritual. Assim, é necessário que o cuidador disponha de tempo para a realização de suas atividades diárias e, também, para a elaboração de estratégias de enfrentamento dos aspectos negativos advindos do processo de cuidar e conviver, pois isso acarreta mudanças, influencia o surgimento de doenças, sobrecarga de responsabilidades e tarefas ao familiar.

Nota-se que, quando há uma mudança da rotina diária, o cuidador começa a vivenciar uma situação muito difícil, como ficou explícito no seguinte discurso:

Então, desde 97 meu pai tem o AVC. Então, no caso, eu era muito criança. Cresci vivendo esta situação de dificuldade. Agora, na minha família desestruturou tudo, porque querendo ou não, ele ficou dependente, ou seja, algumas coisas que ele tinha que fazer, ele tinha que depender de alguém. No caso na fala, tem coisa que ele fala e que você não entende. Aí alguém tem que estar pra interpretar o que ele está falando. Para andar, às vezes, ele precisa de apoio. Ele apoia a mão nos ombros, no caso, ou da minha mãe ou no meu ombro para estar levando onde ele quer ir. Então, assim, o choque maior foi mais pra minha mãe, porque os dois são companheiros até hoje. Eles saíam muito, iam muito na igreja e, depois que ele teve isso, ele... Como se diz? Perdeu a vontade de viver. Não aceita ajuda. Entendeu? Não é porque a família não quer. A família até procura ajudar. Somos em 9 filhos. Somos unidos e sempre ajudamos, incentivemos e falamos: pai, vamos fazer uma fisio, fazer uma fono? Ele mesmo fala: eu já perdi o gosto de viver. Então, ele não sai de casa. Ele não sai de casa pra nada, a não ser só pra ir ao médico ou ao banco só. Tem vergonha dos outros. Não fala. Entendeu? Então, pra gente, isso, como se diz? Foi um susto, porque uma pessoa saudável, sempre trabalhou, gostava de falar, de sair e teve o AVC. Então, não só pra gente, mas pra ele também foi um baque. (p. 12)

Quando se deparam com situações de doença crônica de um idoso na família, sentimentos como medo, preocupação, espanto e aflição são inseridas no seu contexto diário. Percebe-se que essas circunstâncias se dão pela dificuldade da limitação que a doença proporciona, fragilizando-a no decorrer da vida. A vida das pessoas envolvidas é transformada, sendo que ambos necessitam se adaptar às necessidades e ao tempo.

As dificuldades apresentadas ficam evidenciadas quando os cuidados são voltados para o domicílio, e isso causa um transtorno, pois, na maioria das vezes, faltam: experiência, compreensão, conhecimento, paciência e suporte de modo geral.

Salienta-se que grande parte da população idosa, por si só, já se encontra parcialmente dependente, seja de ordem motora, psíquica ou social. Esse grau de dependência realça-se quando o idoso adoece, ficando à mercê dos cuidados familiares.

Depois das experiências por nós comungadas, foi possível perceber a desestruturação do idoso, que, até então, era ativamente saudável e, de repente, se encontra totalmente vulnerável. Fato incontestável o envelhecimento ser um processo natural e cuja evolução pode modificar-se desde que haja ambiente e assistência adequados.

O processo de recuperação e reabilitação pós AVC pode ser prolongado e requer paciência e perseverança por parte do paciente e da família. Dependendo do déficit neurológico específico decorrente do AVC, um paciente em casa pode necessitar de diversos serviços prestados por profissionais de saúde. A família é informada de que o paciente pode se cansar facilmente, pode se tornar irritadiço e contrariado por pequenos eventos, e pode estar menos interessado por eventos do que o esperado ${ }^{15}$. 
O suporte familiar é fundamental para uma prestação de cuidados de qualidade ao membro mais velho. Todavia, prestar cuidados em casa para pessoas dependentes é uma tarefa árdua que pode acarretar consequência para o cuidador e para a família como um todo ${ }^{16}$.

Araújo et al. ${ }^{17}$ afirmam que o cuidador é exposto a eventos diversificados que causam sofrimento. Ele sofre por não saber o futuro do idoso com sequelas de AVC e pelas incertezas quanto à doença $\mathrm{e}$ ao tratamento do AVC. O sofrimento é de ambos, tanto do cuidador como do ser cuidado, pelo fato de vê-lo sofrendo e, também, por sentir-se impotente em se reconhecer incapaz de livrar o outro do sofrimento.

Diante de vários transtornos, o cuidador familiar tem a experiência de se transformar e de se encontrar verdadeiramente na resiliência; e ser resiliente é a capacidade de se aproximar do ser Supremo, pois é por meio desta aproximação que se cresce internamente e se desenvolve uma força pessoal para sair de diversas situações de adversidades. O que reforça este conceito é o estado de superação, ficando evidente nos cuidados prestados, na maneira de conduzir, adaptar-se e enxergar as limitações do idoso.

Destaca-se, também, que a resiliência é uma transformação do ser que proporciona uma entrega, uma aproximação, um encontro com aquele que está fragilizado. Esse modo de ser e agir proporciona mudança de como os enfrentamentos são vivenciados, além de influenciar diretamente aquele que cuida, no que toca sobre como lidar consigo e com o ser cuidado, da transição da doença crônica até o equilíbrio da sua recuperação. Isso pode ser sinalizado na fala:

Significa uma maneira de transformar-se, humanamente falando. De doar-se ao outro, de entregar-se, de amar. Porque o idoso com AVC, ele se torna limitado e nós temos que, de certa forma, adaptarmos a esta limitação. Limitação que nos leva a acreditar que é uma forma de sairmos de nós mesmos. De repente ficarmos numa total entrega. Entrega que exige o ser inteiro da gente naquele momento. É um momento onde nós aprendemos a nos aproximarmos, a encontrar, no meu caso, a mãe como mãe e a filha como filha. (p. 6)

O cuidador desenvolve a sua capacidade de resiliência à medida que se autoavalia frente às dificuldades enfrentadas no cuidado, confronta-se e permite conhecer o que realmente é importante perante a vida que lhe é confiada. Dotado dessas ferramentas, é capaz de dar um novo sentido e mudar de forma significativa sua maneira de ver as coisas e os relacionamentos.

A resiliência é um processo ativo de resistência, reestruturação e crescimento em resposta à crise e ao desafio. A capacidade de superar os golpes do destino ultrajante desafia a sabedoria convencional da nossa cultura: de que o trauma precoce ou grave não pode ser desfeito; de que a adversidade sempre prejudica as pessoas mais cedo ou mais tarde; e de que os filhos de famílias perturbadas ou "destruídas" estão condenados ${ }^{18}$.

Cuidar de um familiar adoecido configura grande responsabilidade e desafio. Novos recursos de enfrentamento precisam ser adotados pela família que se encontra afetada e desestruturada. A partir do significado que atribui ao evento de adoecimento, a família busca um equilíbrio, objetivando adaptar-se à nova realidade e auxiliar na recuperação do familiar acometido por uma doença ${ }^{11}$.

Para Garces et al..$^{19}$, além da capacidade de enfrentar a vida, a resiliência é a capacidade de vencer e sair encorajado de situações adversas e transformado. É um processo que excede o simples "superar" essas experiências, já que permite sair fortalecido por elas, o que, necessariamente, afeta a saúde mental.

Diante de tudo que foi exposto, há toda uma transformação da vida do cuidador familiar, porém a dificuldade da pessoa em aceitar a doença torna o processo de adaptação e recuperação mais comprometedor. Nota-se esse fato por meio do conteúdo explicitado pelo participante a seguir:

Foi uma experiência bastante complicada, porque foi tudo novo. E o que mais achei complicado foi a pessoa aceitar a doença e que ela vai precisar de um tratamento longo pra poder voltar os movimentos. Eu achei que foi, assim, muito complicado em lidar com isso, por que o paciente 
que está com AVC não tem muita paciência pra esperar a recuperação. A gente, às vezes, sem experiência com isso também, ficava meio atribulado e a pessoa também fica, por que a gente quer ver a pessoa melhorar, quer ver a pessoa andando bem, tendo o movimento normal de novo. Só que a recuperação é lenta, dura muito tempo e com muita fisioterapia. Então, a maior dificuldade que eu vi com isso daí, com paciente com AVC, foi isso daí. Foi a pessoa aceitar a doença e aceitar que a recuperação vai ser longa, que a recuperação não vai ser rápida. Foi uma grande dificuldade que nós enfrentamos aqui. Até a gente controlar tudo isso... Até a gente entender, captar a mensagem, já passou muito tempo, já teve muita coisa que aconteceu. A pessoa ficou nervosa. A gente fica nervoso com toda situação. Hoje, nós estamos sabendo controlar bem isso daí, mas passamos muita dificuldade com isso, nesse ponto da pessoa aceitar a doença e ver que a doença tem uma recuperação lenta. Eu acho, assim, que até é bom a pessoa que sai de um quadro desse ter um acompanhamento com um psicólogo pra explicar toda situação, pra preparar a pessoa pra receber isso daí, o que não é fácil. (p. 11)

O grande desafio encontrado em nossa profissão, seja nos cuidados da fisioterapia ou da enfermagem, é nos depararmos com um idoso fragilizado, tanto emocional quanto espiritualmente. Abalado devido à doença, o que dificulta no dia a dia da reabilitação, tratamento e reinserção sociofamiliar, trazendo à tona o desequilíbrio na família. A não aceitação da doença, o constrangimento com o auxílio na higiene e no vestir-se, assim como o fato de se sentir inválido e da alteração da autoimagem, são exemplos de situações relevantes quanto ao não aceitar a condição total ou parcial de dependência.

Para Guedes ${ }^{20}$, as práticas sociais discriminatórias podem restringir substancialmente a autonomia e independência do idoso. Por exemplo, a recusa de emprego ou demissão das pessoas mais velhas; tratá-las como incapazes; recusar-lhes pensões que lhe permitam dar conta das necessidades básicas; no nível institucional, oferecer um ambiente excessivamente despersonalizado, onde a pessoa idosa seja tratada como incapaz, sem poder de decisão e dificultar-lhe o acesso a serviços de saúde.

Outro ponto relevante no âmbito familiar é que o idoso fragilizado, muitas vezes, é obrigado a sair do seu lar e conviver com outro familiar que cuidará dele. Isso pode gerar resistência e dificuldade na reconstrução da vida, e o que era para ser um estreitamento familiar, pode tornar-se uma situação conflituosa.

Por mais que alguns idosos não aceitem a sua dependência, existem muitos que acabam tornandose totalmente dependentes do cuidador, não aceitando cuidados de outras pessoas ou, inclusive, não se esforçando para fazer algumas atividades consideradas impossíveis por eles, acomodandose e provocando transtorno na rotina de vida do cuidador, gerando uma sobrecarga emocional e, consequentemente, um isolamento social ${ }^{21}$.

\section{Considerações finais}

Os resultados do presente estudo permitiram concluir que o cuidador familiar que convive com um idoso com sequelas de AVC assume caráter com implicações do ponto de vista físico, psicológico, social e, sobretudo, na dinâmica familiar.

A família que convive com um idoso debilitado em razão do AVC passa por mudanças inesperadas e, nem por isso, a vida deixa de ter significado. Salienta-se que, diante do desconhecido, surgem respostas que transcendem o eu, desencadeando sentimentos de frustração e fragilidade.

Na maioria das vezes, o cuidador assume um papel de forma isolada. Contudo, diante das mudanças, este sujeito deve ser concebido como um elo entre o ente cuidado, a família assistida e os profissionais de saúde. Dessa forma, o cuidador, mesmo com a nitidez do sofrimento pessoal por estar com dúvidas e incertezas, é fundamental para a equipe multidisciplinar, para que essa, por sua vez, possa traçar intervenções para conduzir as atividades corretas no acompanhamento do idoso e de seus familiares. 
Portanto, sabe-se que o coexistir com o idoso com sequelas de AVC torna-se uma experiência dolorosa, provocada pela enorme mudança de hábito e de vida e pela dificuldade do enfermo em aceitar a doença. Apesar de a maioria dos cuidadores terem relatado que a convivência é uma situação muito difícil, para outros, ocasionou uma transformação do ser e uma aproximação com aquele que está fragilizado, o que chamamos de resiliência.

\section{Colaboradores}

Rogério Donizeti Reis e Elaine Cristina Pereira participaram ativamente na elaboração, preparação, coleta, análise, interpretação dos dados e na discussão dos resultados. Os demais autores contribuíram de forma igualitária na discussão, revisão e aprovação da versão final do manuscrito.

\section{Referências}

1. Araújo I, Santos A. Famílias com um idoso dependente: avaliação da coesão e adaptação. Rev Enferm Ref. 2012; 3(6):95-102.

2. Fabrício SCC, Rodrigues RAP. Revisão da literatura sobre fragilidade e sua relação com o envelhecimento. Rev Rene. 2010; 9(2):113-9.

3. Instituto Brasileiro de Geografia e Estatística. @Cidades [Internet]; 2014 [citado 10 Jun 2014]. Disponível em: http://www.ibge.gov.br/home/.

4. Gomes MJAR. Vidas após um acidente vascular cerebral: efeitos individuais, familiares e sociais. Portugal. [Tese]. Minho: Universidade do Minho; 2012.

5. Ministério da Saúde (BR). DATASUS. Banco de dados do Sistema Único de Saúde [internet]; 2016 [citado 06 Jul 2016]. Disponível em: www.datasus.gov.br.

6. Girardon-Perlini NMO, Hoffmann JM, Piccoli DG, Bertoldo C. Lidando com as perdas: percepções de pessoas incapacitadas por AVC. REME. 2007; 11(2):149-54.

7. Araújo JS, Silva SED, Santana ME, Vasconcelos EV, Conceição VM. A obrigação de (des) cuidar: representações sociais sobre o cuidado a sequelados de acidente vascular cerebral por seus cuidadores. REME. 2012; 16(1):98-105.

8. Monteiro I. Antropologia: uma nova concepção. Petrópolis: Vozes; 2007.

9. Bardin L. Análise de conteúdo. São Paulo: Edições 70; 2011.

10. Mendonça FF, Garanhani ML, Martins VL. Cuidador familiar de sequelados de acidente vascular cerebral: significados e implicações. Rev Saude Colet. 2008; 18(1):143-58.

11. Paiva RS, Valadares GV. Circunstâncias que influenciam na significação da alta hospitalar: estudo de enfermagem. Esc Anna Nery. 2013; 17(2):250-62.

12. Pereira RA, Santos EB, Fhon JRS, Marques $S$, Rodrigues RAP. Sobrecarga dos cuidadores de idosos com AVC. Rev Esc Enferm USP. 2013; 47(1):185-92. 
13. Ohara ECC, Ribeiro MP, Concone MHVB. Saúde da família: considerações teóricas e aplicabilidades. 2a ed. São Paulo: Martinari; 2010.

14. Pavin RS, Carlos SA. A qualidade de vida de cuidadores informais de idosos hospitalizados. RBCEH. 2013; 10(3):242-55.

15. Smeltzer SC, Bare BG, Hinkle JL. Brunner \& Suddarth tratado de enfermagem médico-cirúrgica. Rio de Janeiro: Guanabara Koogan; 2011.

16. Salgueiro $H$, Lopes $M$. A dinâmica da família que coabita e cuida de um idoso dependente. Rev Gaucha Enferm. 2010; 31(1):26-32.

17. Araujo JS, Silva SED, Santana ME, Conceição VM, Vasconcelos EV. O processo do cuidar/cuidado nas representações sociais de cuidadores de pacientes sequelados por acidente vascular cerebral. Enferm Foco. 2011; 2(4):235-8.

18. Walsh F. Bases de abordagem da resiliência familiar. In. Walsh F. Fortalecendo a resiliência. São Paulo: Roca; 2003.

19. Garces SBB, Krug MRO, Hansen D, Brunelli AV, Costa FTL, Rosa CB, et al. Avaliação da resiliência do cuidador de idosos com Alzheimer. Rev Bras Geriatr Gerontol. 2012; 15(2):335-52

20. Guedes SICM. Cuidar de idosos com dependência em contexto domiciliário: necessidades formativas dos familiares cuidadores. [Dissertação]. Porto. Escola Superior de Enfermagem do Porto; 2011.

21. Areosa SVC, Henz LF, Lawisch D, Areosa RC. Cuidar de si e do outro: estudo sobre os cuidadores de idoso. Rev Saude Doenca. 2014; 15(2):482-94.

Reis RD, Pereira EC, Pereira MIM, Nassar AM, Soane C, Silva JV. Significados para los familiares de convivir con un anciano con secuelas de Accidente Cerebrovascular (AVC). Interface (Botucatu). 2017; 21(62):641-50.

El objetivo de este estudio es identificar los significados para los familiares de convivir con una persona anciana de la familia con secuelas de AVC. Los participantes del estudio fueron los familiares que convivían con un anciano con secuelas de AVC del genero masculino y femenino. La muestra estaba formada por 15 miembros de la familia. Los instrumentos utilizados para la colecta de datos fueron: cuestionario referente a la caracterización personal y familiar de los participantes y el guión de entrevista semi-estructurada. Para la extracción de las ideas principales se utilizó el Análisis de Contenido de Bardin. As categorías emergentes del tema 'Significado de convivir' fueron: 'Experiencia dolorosa', 'Cambio de hábito y de vida, 'Una situación muy difícil', 'Ser resiliente' y 'Dificultad de la persona para aceptar la enfermedad. Se concluye que convivir con ancianos con secuelas de AVC asume carácter con implicaciones físicas, psicológicas y familiares

Palabras clave: Anciano. Acidente cerebrovascular. Familia. 